\title{
SAINDO DO ARMÁRIO: A HISTÓRIA DO MOVIMENTO LÉSBICO EM MACEIÓ
}

\author{
COMING OUT: THE HISTORY OF THE LESBIAN MOVEMENT IN MACEIÓ
}

\section{Resumo}

O objetivo deste artigo é retratar parte da história do movimento lésbico da cidade de Maceió, a partir dos repertórios de militantes que atuaram entre 1990 e 2000 na cidade. Caracteriza-se como uma pesquisa qualitativa, com a utilização de entrevistas semiestruturadas com cinco militantes atuantes no período de emancipação e fortalecimento do movimento na cidade. Além disso, foi realizada uma revisão bibliográfica acerca do movimento lésbico no contexto brasileiro, a fim de construir um panorama entre a história local e o movimento nacional. A pesquisa realizada nos remete a um tipo de sociedade marcada fortemente pelo modelo patriarcal que invisibiliza e oprime as experiências das mulheres, em especial das mulheres lésbicas. Desse modo, o retrato dessas histórias possibilita a visibilidade da força das mulheres lésbicas que atuam no movimento colocando-as como protagonistas de suas vidas e lutas.

Palavras-chave: Movimento de Mulheres Lésbicas. Heteronormatividade. Movimento LGBT. Feminismo.

\begin{abstract}
The goal of this article is to portray the History of the lesbian movement in the city of Maceio, based on the speeches of some activists which were engaged on it from the years of 1990 to 2000 . It is characterized as a qualitative research using semi-structured interviews with five activists that were on stage in the period of the emancipation and strengthening of the lesbian movement in the city of Maceió. In addition, it was made a bibliographic review about the movement on national context in order to build parallel between both: local and national History. This research brings us a kind of society that is strongly influenced by the patriarchal model and makes women invisible and oppresses their experiences, particularly the lesbian ones. Whereas, the portraying of these stories enables visibility and protagonism to the strength possessed by the lesbian women resisting on the movements, also their lives and fights.
\end{abstract}

Keywords: Movement of Lesbians Women. Heteronormativity. LGBT Movement. Feminism.

Mariana Duarte Oliveira

Universidade Federal de Alagoas (UFAL). E-mail: mmduarte.o@gmail.com

Marcos Ribeiro Mesquita

Universidade Federal de Alagoas (UFAL). E-mail: marcos.mesquita@ip.ufal.br 


\section{Introdução}

Há muitas formas de se narrar histórias e estas são atravessadas pelos significados, pelas experiências e pelos contextos nos quais elas são construídas. Quando pensamos na história das mulheres, de um lado torna-se inevitável associála ao silenciamento, à opressão e à violência, em suas diversas formas. Por outro lado, temos as resistências, as lutas e as conquistas de direitos, mesmo em um tempo marcado por retrocessos e por uma sociedade que ainda se pauta em um modelo patriarcal que prescreve comportamentos e regras a serem seguidas por homens e mulheres.

Ao se falar das histórias de mulheres lésbicas, compreendemos que elas são duplamente invisibilizadas: primeiro, por serem mulheres e segundo, por confrontarem a heteronormatividade. Wittig (2004) discute, em uma de suas obras, que as lésbicas fogem das normas impostas, não se enquadrando econômica, política e ideologicamente à "categoria mulher", considerando, para isso, um contexto de dominação masculina no qual essa relação implica em obrigações pessoais, físicas e econômicas.

Silva (2006) aponta que a visibilidade, no caso de minorias, pode ser considerada uma estratégia política que trabalha no sentido de romper preconceitos e tabus. O autor afirma que, se por um lado é essencial uma pessoa perceber-se enquanto ator/atriz capaz de lutar por seus direitos, por outro, este reconhecimento deve se materializar em participação política que possibilite a esse sujeito reconhecer a existência de outros iguais. Dessa maneira, podemos compreender que quando uma mulher lésbica passa a se reconhecer enquanto sujeito político, ela faz um movimento importante na sua luta por direitos.

Dito isso, compreendemos a importância de reviver, rememorar e contar as histórias de luta das mulheres lésbicas de modo a fortalecer suas pautas e demandas específicas - tão invisibilizadas ao longo da história -, tanto pelo movimento de lésbicas, gays, bissexuais, travestis e transexuais (LGBT), como pelo movimento feminista. Durante a nossa trajetória de pesquisa, não encontramos nenhum trabalho ou documentos pertencentes aos grupos que nos remetesse à trajetória do movimento lésbico em Maceió. Desta maneira, este trabalho, reconstrói parte da história desse movimento através das narrativas de cinco mulheres militantes entre as décadas de 1990 e 2000.

Esta pesquisa caracteriza-se por sua dimensão qualitativa, cujos dados foram produzidos através da utilização de entrevistas semiestruturadas. Além disso, foi realizado um levantamento bibliográfico referente às produções científicas sobre o movimento lésbico no contexto brasileiro, a fim de traçar um breve panorama entre o movimento local e nacional.

Utilizou-se como critério de inclusão, mulheres que atuam ou tenham atuado no movimento lésbico de Maceió entre as décadas de 1990 e 2000, visto que, de acordo com informações de militantes, foi durante este período que nasceu o movimento na 
cidade. A delimitação de cinco mulheres para a realização desta pesquisa possibilitou uma conversa mais longa com as participantes e uma análise mais aprofundada de seus discursos. Para assegurar o anonimato das entrevistadas, cada entrevista foi identificada com um código de acordo com a ordem cronológica de sua realização (E1, E2, E3, E4 e E5).

O primeiro contato foi estabelecido com uma ex-militante da Liga Brasileira de Lésbicas e precursora do movimento na cidade. A partir dela, foi possível estabelecer o contato com as demais participantes. $\mathrm{O}$ instrumento para a coleta dos dados foi composto por 18 questões discursivas referentes às suas trajetórias no movimento lésbico, às suas conquistas e aos desafios na participação política; também, às divergências e parcerias com outros grupos do movimento LGBT, às suas formas de diálogo com a sociedade em geral e à existência de grupos lésbicos na cidade.

As narrativas foram gravadas em áudio e posteriormente transcritas, sendo analisadas a partir da Análise de Conteúdo. Baseando-se nos objetivos préestabelecidos, os discursos das participantes foram divididos em quatro categorias, sendo: constituição dos grupos lésbicos; conquistas do movimento lésbico de Maceió; dificuldades na participação política; e articulações e divergências com outros grupos e movimentos LGBTs.

Buscou-se com este trabalho enfatizar as histórias e narrativas dessas mulheres e afirmar suas ações políticas, a fim de contrapor os mecanismos de exclusão, existentes inclusive no meio LGBT, que contribuem para a manutenção de hierarquias e a própria invisibilidade lésbica. Além disso, espera-se que este trabalho também possa servir como um instrumento que dê visibilidade à história do movimento lésbico maceioense.

\section{Breve contextualização do movimento lésbico nacional}

O movimento de mulheres lésbicas, ao longo de sua história, é atravessado por divergências com o movimento LGBT, formado predominantemente por homens. Com o movimento de mulheres feministas, devido à falta de reconhecimento de suas especificidades, evidencia-se um caráter heteronormativo e patriarcal, inclusive, dentro de movimentos voltados às "minorias".

De acordo com Facchini (2005), este movimento começou a ser delineado no Brasil em meados dos anos 1970, sendo compreendido, nesse contexto, como um conjunto de associações e entidades mais ou menos institucionalizadas, com o objetivo de defender e garantir os direitos referentes à livre orientação sexual e/ou reunir, para fins políticos, indivíduos que se reconhecessem a partir de qualquer identidade sexual tomada como sujeito desse movimento. Destaca-se nesse período, o Somos - Grupo de Afirmação Homossexual - em São Paulo, considerado o primeiro grupo brasileiro formado, em um primeiro momento, exclusivamente por homens. Ainda segundo a autora, sua primeira aparição pública em uma semana voltada a debates 
sobre movimentos de emancipação de grupos discriminados, na Universidade de São Paulo (USP), possibilitou a mobilização de novos integrantes, incluindo mulheres, engajados/as no movimento por lutas políticas, e a criação de novos grupos.

As mulheres inicialmente não pleiteavam tratamento diferenciado, partindo da ideia de uma igualdade total, porém, a falta de espaço para a discussão de suas especificidades, dentro de um ambiente predominantemente masculino, provocou a mobilização dessas mulheres para que pudessem ter pelo menos um subgrupo exclusivo para lésbicas. Isso não só deu início a um processo de emancipação dessas mulheres como também as aproximou dos grupos feministas atuantes em São Paulo desde a década de 1970. Martinho (2005) aponta que a ruptura com o grupo Somos levou à criação do primeiro grupo lésbico, o Lésbico-Feminista (LF), em 1979, que foi substituído por Grupo de Ação Lésbico-Feminista (GALF) dois anos depois.

Autoras como Soares \& Sardenberg (2011) apontam que muitas lésbicas integraram o movimento feminista brasileiro desde seu início, ao considerar o caráter libertário desse movimento, que defende, entre outras coisas, a liberdade das mulheres, a expressão da sexualidade e o direito ao prazer sexual, tornando-o um ambiente favorável às descobertas. No entanto, as mulheres feministas relutaram, inicialmente, a incorporar as questões das lésbicas em sua produção teórica e agenda política devido à pressão social da conjuntura da época, que exigiu o silenciamento da lesbianidade. Martinho (2005) acrescenta que a política do movimento feminista para lésbicas, durante as décadas de 1980 e 1990, foi a da invisibilidade. As feministas homossexuais, em número razoável dentro desse movimento, ou simplesmente se omitiam sobre a questão lésbica ou hostilizavam abertamente todas as tentativas de politização do assunto.

Segundo Selem (2007), no decorrer dessas últimas três décadas, muitos grupos surgiram, ao passo que outros acabaram ou foram esquecidos por falta de registros. $\mathrm{O}$ GALF (SP), o Grupo Terra Maria Opção Lésbica (SP), Grupo Libertário Homossexual (BA), Grupo Gaúcho de Lésbicas Feministas (RS), Coletivo de Lésbicas do Rio de Janeiro (COLERJ), Grupos Safos (PR), DIVAS - Grupo pela Diversidade Sexual (PE), Grupo Afirmativo de Mulheres Independentes - GAMI (RN), entre outros, são alguns exemplos de grupos que explodiram em décadas diferentes no país. Estas distintas nomeações de grupos e coletivos também refletem a diversidade existente dentro do próprio conjunto generalista denominado "mulher" e "lésbica".

As décadas de 1990 e 2000 vieram como diferenciais para a história do movimento de lésbicas e o fortalecimento de sua autonomia, pois apesar da existência desses grupos desde o final da década de 1970, essa trajetória foi marcada por rupturas e fragilidades, decorrentes da dificuldade de essas mulheres tomarem seu lugar enquanto sujeito político.

Em 1996, foi organizado o primeiro Seminário Nacional de Lésbicas (SENALE), como um espaço dialógico para proposições e deliberações das lésbicas de várias regiões do país. De acordo com Selem (2007), a partir do V SENALE, o dia 29 de agosto passa a ser considerado pela maioria das militantes como o "Dia Nacional da Visibilidade Lésbica”, contando com projetos de lei em vários estados. Também 
durante este Seminário foi formalizada a criação da Liga Brasileira de Lésbicas (LBL), entidade agregadora de grupos, ONGs e associações, objetivando o empoderamento destas, sejam elas de grupos mistos ou de grupos exclusivamente lésbicos, conforme apontado por Lessa (2007). Após esse ano, o evento já havia ocorrido em Salvador (BA), Betim (MG), Aquiráz (CE), São Paulo (SP), Recife (PE), Porto Velho (RO), Porto Alegre (RS), Brasília (DF) e Teresina (PI).

Para Soares \& Costa (2012), a partir da década 2000, o movimento lésbico passou a adotar uma performance mais propositiva e continuada na agenda política do movimento feminista brasileiro, participando de ações promovidas por organizações como: Articulação de Mulheres Brasileira (AMB), Rede Nacional Feminista de Saúde, Direitos Sexuais e Direitos Reprodutivos (RFS); construindo pautas conjuntas nas Conferências Nacionais de Políticas para as Mulheres Brasileiras e na Plataforma Política Feminista; na Campanha por uma Convenção Interamericana dos Direitos Sexuais e dos Direitos Reprodutivos, através de parceria com AMB e Centro LatinoAmericano em Sexualidade e Direitos Humanos (CLAM), no aumento da presença nas Paradas do Orgulho LGBT e das atividades da visibilidade lésbica no 29 de agosto.

Em Maceió, também se formaram grupos exclusivamente lésbicos, porém, muitos acabaram sem ter o registro escrito de suas lutas. Devido a ausência de documentos, o presente artigo busca evidenciar a história do movimento lésbico na cidade, a partir das narrativas e memórias de militantes, destacando a contextualização dos momentos históricos nos quais os grupos lésbicos se constituíram: a dificuldade na participação política, as conquistas obtidas através do movimento lésbico e as divergências com outros grupos do movimento LGBT.

\section{Constituição dos grupos lésbicos em Maceió}

Os relatos demonstram que, apesar do registro da existência de grupos lésbicos no Brasil desde o final dos anos 1970, e em Maceió, na década de 1990, as problematizações acerca da lesbianidade ainda eram incipientes. A discussão do movimento feminista na cidade girava, basicamente, em torno da igualdade de gênero no mercado de trabalho, sendo estas as pautas que o movimento feminista nacional discutia entre os anos 1960 e 1980.

As primeiras militantes lésbicas inseriram-se no movimento misto ${ }^{1}$, como era intitulado no final dos anos 1990, a fim de debater direitos sexuais e a importância da mobilização das mulheres para atuar dentro do movimento. Na época, o único segmento homossexual existente era o Grupo Gay de Alagoas (GGAL), cujas pautas giravam em torno de políticas específicas de enfrentamento do HIV/AIDS e em torno da violência homofóbica. Desse modo, as mulheres presentes no movimento

1 Movimento misto era o termo utilizado para os movimentos homossexuais compostos por homossexuais masculinos e femininos. 
homossexual, predominantemente masculino, começaram a problematizar acerca da invisibilidade de suas demandas.

Como afirma Pinafi \& Peres (2010), a trajetória da militância entre gays e lésbicas é marcada por uma série de conflitos vinculados a certos traços de misoginia e lesbofobia, em que essas mulheres perceberam que havia uma grande diferença entre ser uma mulher lésbica e ser um homem gay em uma sociedade patriarcal e sexista. E isso se torna claro ao visualizarmos que o início do movimento lésbico em Maceió ocorre cerca de vinte anos após a criação do primeiro grupo de mulheres lésbicas em São Paulo e, mesmo assim, ainda carrega a bandeira da invisibilidade de suas necessidades.

Dentro dessa discussão, aparece em uma das falas das entrevistadas, o $X$ Encontro Brasileiro de Gays, Lésbicas e Transgêneros, ocorrido na cidade de Maceió em 2001, como um marco inicial para a importância da invisibilidade lésbica no movimento LGBT. O evento reuniu militantes de todo o Brasil, contudo, estiveram presentes apenas cerca de quatro militantes mulheres de Maceió.

Esse congresso aqui em Alagoas foi histórico porque as mulheres tinham acabado de vir do SENALE que é o Seminário Nacional de Lésbicas e é dentro do Congresso que começava a polarizar a discussão da autonomia das mulheres dentro do movimento. E há uma decisão das mulheres em começar a organizar uma rede específica para tratar das especificidades das lésbicas. Então 2001 é que vai ter essa problematização de uma forma muito mais visível (E1).

Assim, no início dos anos 200o, começa-se a refletir a possibilidade de criação de um grupo exclusivamente lésbico para discutir questões específicas. A primeira tentativa de criação originou o Grupo Alagoano de Lésbicas (GAL), formado por cerca de seis mulheres. Este, porém, não conseguiu se manter, atuando somente por volta de quatro meses.

A necessidade de uma articulação nacional de uma rede específica de lésbicas tomou uma proporção maior e, em 2003, no próprio SENALE, começou-se a discutir a importância da visibilidade de forma organizada. Após o fim do GAL, as militantes permaneceram por um período de tempo sem grupo. A articulação para uma nova formação se deu através de um projeto de extensão - Surto Cultural - coordenado por uma das mulheres na Universidade Federal de Alagoas (UFAL). Através da Incubadora Social - um programa alocado na UFAL que coordenava ações empreendedoras - o Surto Cultural foi convidado a apresentar um projeto social; originando, em 2003, a Organização de Mulheres Maria Mariá. Apesar de não se autodenominarem como um grupo lésbico, suas ações também eram direcionadas a esse público, como por exemplo, a organização da primeira Semana da Visibilidade Lésbica, ocorrida em 2004, articulada à programação da Parada Gay [Da diversidade]. Segundo um dos 
relatos, 2004 foi o único ano, em Maceió, em que houve um trio especificamente organizado e protagonizado por lésbicas.

Inicialmente, a Maria Mariá foi formada por um grupo de ex-estudantes, objetivando a reflexão acerca do que é ser mulher e a sua emancipação, principalmente em relação à mulher alagoana, visto que Alagoas ainda carrega uma herança oligárquica e coronelista. Devido ao estado ocupar o $2^{\text {o }}$ lugar no ranking nacional de violência contra a mulher, o grupo deu maior destaque a esta problemática. Por volta de 2012, a organização interrompeu suas atividades.

Bem, a Maria Mariá era um grupo de ex-estudantes. A gente foi do movimento estudantil e aí a gente acabou se aproximando pela identidade, pelos questionamentos à ordem vigente, a ordem patriarcal, a ordem econômica capitalista, e aí a gente achava que precisava de um espaço de militância. Tinha o movimento estudantil, mas depois cada uma se formou e foi cuidar da sua vida e aí a gente precisava de algo de grupo, algo que fosse mais coletivo, algo que tivesse um projeto coletivo, então o Maria Mariá surge como isso, como uma perspectiva de se pensar, de se questionar esse papel da mulher e de pensar em alternativas para mulher em Alagoas, um estado pobre, rico em belezas naturais, mas um estado pobre quando a gente vai pensar na questão da cultura e dos valores; um estado bastante atrasado, ainda com o coronelismo bastante presente (E2).

A Associação de Mulheres Maria Mariá buscava estabelecer diálogos com distintos movimentos sociais, como o Movimento Negro e a Liga Brasileira de Lésbicas (LBL), tendo, inclusive, uma de suas componentes como militante da Liga. Embora não houvesse um núcleo específico da LBL em Alagoas, cerca de cinco militantes de Maceió ainda transitaram nesse espaço. Contudo, esse campo de interlocuções entre os movimentos sociais também se apresenta como um campo de tensões à medida que outros poderes tentam deslegitimar as mulheres envolvidas no processo de luta e resistência.

Qual é a discussão que surge em torno dos grupos? O grupo da universidade que era a Maria Mariá, era muito elitista pelo fato de estar na universidade, então existia um discurso de muitos, principalmente dos homens, muito mais na intenção de destituir o poder do outro, sabe? Ah, esse grupo é muito elitista, só faz trabalho com a universidade, mas as meninas que nós buscávamos nos aproximar a priori eram as meninas da periferia. O fato de estarmos na universidade, localizadas na universidade, era uma oportunidade de termos uma sede e ter todo um aparato de consultoria da administração, da contabilidade e tal, que a Incubadora nos oferecia (E1). 
Surgiu alguns anos depois, por volta de 2009, o grupo de lésbicas Dandara, uma formação sem vinculação com espaços institucionalizados, iniciada por mulheres da periferia de Maceió, dentro do Grupo Gay Afrodescendente Filhos do Axé. Inicialmente formado por apenas três mulheres, o nome escolhido remeteu-se a um resgate da imagem de Dandara, uma liderança feminina negra. A ideia inicial de sua formação, na verdade, foi direcionada ao time de futsal feminino em que elas atuavam no sentido de promover consciência política às integrantes do time, buscar melhorias e visibilidade ao esporte feminino em Alagoas. Para além, as desigualdades e práticas lesbofóbicas e machistas, enfrentadas durante a vida dessas mulheres, também são resgatadas como propulsoras da vontade de luta e da necessidade de reconhecimento do segmento lésbico.

Durante toda a minha adolescência, eu sofri não só o bullying, mas a lesbofobia mesmo. Primeiro da família, que aí eu tive que desafiar a mim mesma para enfrentar esse preconceito. E aí quando meu pai descobriu, ele me viu na televisão, num protesto, e aí a repórter me chamou: 'e aí o que você tem a falar sobre o dia da visibilidade lésbica?' [...]. Quando eu cheguei em casa, meu pai já estava com as bolsas arrumadas. [...]. Então, todo processo de luta foi a partir daí, porque não abaixei a cabeça, queria provar pra mim mesma que não queria nascer morta, que queria viver, e pra ele, que além da filha lésbica, ele tinha uma militante, uma guerreira $\left(\mathrm{E}_{4}\right)$.

Os discursos apontam uma crescente fragilidade na constituição do movimento LGBT em Maceió, em especial dos grupos exclusivamente lésbicos, caracterizando-os como grupos efêmeros devido à falta de apoio à militância feminina que é atravessada por constantes embates com órgãos gestores e até mesmo com outros grupos LGBTs, dificultando a visibilidade e efetivação de suas ações. Machado (2007) considera essencial o apoio do Estado em relação às formas de incentivo para fortalecimento das ONGs e movimentos sociais, porém defende que estes mantenham a sua autonomia, uma vez que são considerados os tradutores das demandas das bases sociais e os responsáveis por confrontar as políticas do Estado com o conhecimento sobre a vida objetiva e sobre as condições de opressão que cada grupo sofre.

Ao iniciar a militância em Maceió e entrar em contato com outros grupos ativos na cidade, como a Organização de Mulheres Maria Mariá, o grupo Dandara ampliou seus debates à sociedade em geral, ocupando um espaço de referência enquanto movimento lésbico. Uma das componentes do grupo Dandara ainda tentou formar o seu próprio grupo, Mulheres de Raízes, porém, não houve componentes suficientes para dar continuidade. O grupo Dandara é o único que ainda se mantém no cenário político de Maceió enquanto movimento lésbico, embora tenha havido uma desmobilização das militantes. 
É interessante destacar, nesse ponto, a presença de uma militância voltada, em especial, para as camadas urbanas de baixa renda da população, que busca a visibilidade de mulheres lésbicas, negras e periféricas como sujeitos políticos. Para Oliveira (2007), ao assumir uma identidade negra, lésbica ou negra lésbica, essas mulheres expressam a consciência de que estão envolvidas em determinadas relações de poder que exigiriam um compromisso com a luta contra a opressão.

\section{Dificuldades na participação política}

O termo movimento gay ou homossexual foi utilizado por muito tempo como aquele que contemplava todos os segmentos minoritários. Contudo, as mulheres militantes não se identificavam com tal termo, pois este excluía qualquer outro segmento como o das lésbicas, das travestis e dos/as transexuais. $\mathrm{O}$ objetivo das mulheres lésbicas não era fragmentar o movimento, mas destacar a perspectiva de que cada sujeito é portador de suas demandas e que cada segmento desses é um universo com especificidades que precisam ser primeiramente reconhecidas para, então, serem articuladas e discutidas com o coletivo.

Se nós não sabíamos, enquanto movimento, quais eram as nossas principais pautas e, principalmente, quais eram as nossas principais dores, certamente os outros movimentos não iriam nos reconhecer. Então era muito mais um processo de unificar as nossas pautas e sentíamos que discutir a saúde das lésbicas era diferente de discutir a saúde dos gays, porque eles traziam demandas, principalmente, no campo do enfrentamento à epidemia da AIDS e, para nós, era muito mais a questão do acolhimento, a questão da drogadição. [...] E segundo, a questão da invisibilidade, da manutenção dos segredos desnecessários que terminam rompendo e fragilizando vínculos. Porque se você tá o tempo todo reprimindo e escondendo o que você é, como você vai se fortalecer enquanto sujeito? (E1).

A eclosão da epidemia da AIDS, em 1980, conhecida como "peste gay", implicou em maior visibilidade da homossexualidade e em ações mobilizadoras contra a epidemia pelos militantes homossexuais. No entanto, nesse cenário, de acordo com a fala de uma das militantes entrevistadas, as lésbicas ainda permaneciam invisibilizadas pelo Ministério da Saúde (MS), que argumentava que epidemiologicamente elas não existiam. Selem (2007) corrobora esse posicionamento ao afirmar que o discurso médico nem considerava a possibilidade de Infecções Sexualmente Transmissíveis (ISTs) entre mulheres, pois o pênis ainda determinava a existência da "verdadeira relação sexual”. 
Como uma das representantes do movimento Maria Mariá colocou, "o silêncio caracteriza-se como um mecanismo de defesa do conservadorismo". A sociedade é permeada por preconceitos velados. Ao mesmo tempo em que se ouve, diariamente, notícias sobre homossexuais agredidos e/ou assassinados, mulheres em situação de violência doméstica e/ou sexual e situações envolvendo a morte de jovens negros, veicula-se que não há preconceito, não há discriminação sexual, tampouco racial. A cultura política patriarcal e proibitória também aparece como herança social, dificultando que esses sujeitos assumam lugares e vozes. Algumas mulheres acabam preferindo manter-se no anonimato por medo de serem perseguidas após a visibilidade.

Olha, tanto no feminismo quanto na questão das lésbicas, a grande dificuldade é que parece assim, que infelizmente a sociedade criou, o que aconteceu um pouco com o movimento negro, né? Que é tipo, quando o Obama é eleito, então tipo, não existe mais preconceito, hoje nós temos até um presidente negro, que é presidente dos EUA, a maior potência do mundo, então não tem racismo, não tem preconceito. E aqui é a mesma coisa, hoje nós temos uma presidenta que é mulher, aí hoje na novela fica passando, aí assim, parece que hoje está tudo resolvido, quando a gente sabe que não tá, até porque a gente sabe que o preconceito ele é escondido, não é exposto, é fingido. 'Ah tá tudo bem, desde que não seja com meu filho' (E2).

Estas mulheres acabam silenciando-se por medo da represália de amigos, da família e da sociedade que as forçam a permanecer isoladas e "escondidas em um armário”. Ao lidar com a sexualidade, adentra-se, para além da esfera política, na esfera íntima do sujeito.

A gente fazia panfletagem, tudo, pra ver se a gente conseguia, mas era muito difícil aí eu até fiz a proposta: 'a gente não diz que é movimento lésbico, ou melhor, a gente não diz que é direcionado a lésbicas, a gente faz outra argumentação'. Tem muita gente que é, mas debaixo dos panos. Poxa, ou você é ou você não é, minha gente. Umas diziam que eram os pais, outras que era o trabalho, outras diziam que era o estudo. Vem cá, qual é o problema? Você tem que ser o que você é (E3).

Segundo as militantes entrevistadas, a visibilidade, embora seja uma das bandeiras de luta do movimento, era (e ainda é) uma das principais dificuldades em fortalecer o movimento lésbico. Ela torna-se um paradoxo para o movimento de mulheres lésbicas em Maceió. Ao mesmo tempo em que é uma bandeira de luta necessária para que suas especificidades e demandas sejam visibilizadas, ela provoca o medo em algumas mulheres de serem conhecidas por serem mulheres lésbicas e, consequentemente, em militarem por essa causa. 
Isso porque elas sabem o que é ser duplamente oprimidas - primeiro por serem mulheres e, segundo, por serem lésbicas. E em alguns casos isso ainda triplica; quando se é mulher, lésbica e negra. Em 2014, o único grupo existente, o Dandara, contava com cerca de cinco componentes, entre as quais, três eram mais ativas. Marcelino (2016) afirma que

O fato de ser lésbica torna as mulheres homossexuais ainda mais vulneráveis às diversas formas de violências cometidas contra as mulheres. O 'mito do silêncio' ganha força a partir do momento em que essa oposição normal e contra a natureza no campo da sexualidade dita uma regularização das práticas sexuais. Silencia-se o sexo e a sexualidade, omite-se a violência e por estar contida numa relação de poder, o controle do corpo se torna o alvo da sociedade. A heterossexualização imposta a o corpo lésbico constitui essa invisibilidade e silenciamento vinda de instrumentos tão poderosos que adentram na domesticação do corpo, nas práticas de ensino, na punição. O medo é um elemento comum e daí é compreensível entender o abismo que há entre as denúncias da violência e a visibilidade da homossexualidade (Marcelino, 2016: 126).

Além da desmobilização feminina, não há recursos financeiros ou infraestrutura adequada que comporte as reuniões, as quais geralmente ocorriam nas casas de alguma militante. Selem (2007) ainda nos diz que a desorganização na formação de grupos exclusivamente lésbicos não é algo raro, visto que nessa sociedade, muitas vezes um grupo de mulheres é menosprezado, tendo em vista a representação delas como categoria inferior em detrimento ao homem, empoderado pela patriarcalidade. Para exemplificar, uma das militantes relembra:

Tem uma cena histórica pra gente na primeira semana da visibilidade lésbica que aconteceu em 2004. O auditório lotado. Nós tínhamos quase 100 pessoas para a primeira semana da visibilidade lésbica. Quando os jornalistas chegaram para registrar, inclusive tinha jornalistas daqui de Maceió, do Rio de Janeiro, de São Paulo, as mulheres correram todas para trás das cortinas. Foi impressionante. Eu lembro que eu estava coordenando a mesa e quando eu olhei, 'oxe, peraí tá pegando fogo?', aí foi que eu me dei conta que eram os jornalistas que estavam se posicionando para tirar foto e as mulheres correram. Então, o medo da visibilidade mesmo, né? De aparecer enquanto lésbica, né? Seja na família, no trabalho, nos espaços sociais, ele é muito presente. Esse é um aspecto que ainda hoje reverbera negativamente (E1). 
Essa reverberação não se limita somente à constituição do movimento lésbico, mas também a outras esferas de suas vidas, como por exemplo, no contexto da saúde das mulheres lésbicas.

Acho que uma coisa que as mulheres sempre relatam e aí existe a resistência de irem ao ginecologista. O acolhimento a mulheres heterossexuais em relação à saúde reprodutiva é diferente do acolhimento a mulheres lésbicas. Eu não sei se você viu, se estava na oficina na hora que a coordenação do CTA de um determinado município disse que não conseguia fazer a abordagem, que as mulheres não chegam ao médico, não vão fazer prevenção, por conta da concepção de que elas não precisam tratar da saúde sexual reprodutiva porque elas não transam com homens, mas é principalmente as perguntas que inibem né? Usa camisinha? Eu lembro que uma vez fui pra um ginecologista, troquei de ginecologista e ele fez a primeira pergunta: já engravidou? Não, só transo com mulheres. Já fez aborto? Não, só transo com mulheres. E ele continuava fazendo essas perguntas. Ele nem olhava na minha cara! E isso não aconteceu só comigo. Temos vários relatos nessa perspectiva. Isso é uma lesbofobia velada. E se as mulheres não se posicionam, não reclamam, não vão a Ouvidoria, é óbvio que esses profissionais vão continuar tratando dessa forma (E1).

Em contrapartida ao medo, a socialização das situações de opressões cotidianas

torna-se metodologia para fortalecer a confiança e identidade do grupo, ensejando a luta política. Ou seja, é o próprio enfrentamento, a consciência da necessidade de uma organização coletiva, ações de conscientização referentes a práticas machistas e lesbofóbicas, como passeatas e a Parada da Diversidade, assim como citadas pelas militantes, que podem possibilitar mudanças.

\section{Conquistas do movimento lésbico}

Para algumas militantes de Maceió, o próprio reconhecimento dos grupos que abordam a temática lésbica, como o Dandara e a Associação Maria Mariá, e a menção a estes em notas de jornais locais quando se fala em visibilidade lésbica, já são consideradas conquistas diante da realidade do estado. Para outras, ainda não há conquistas a serem consideradas e sim lutas a serem travadas.

Eu acho que ainda não foi nada conquistado. Acho que o movimento em si ainda está engatinhando, não tem conquistado ainda. Nada mesmo, principalmente aqui que é um estadozinho de coronel, do voto de cabresto, onde ninguém pensa... Não é interessante para os governantes que a população em si estude, 
tome conhecimento pra si, e aqueles poucos que tem acesso a uma educação de qualidade não querer trabalhar, não querem viver de militância (E5).

Embora não tenha sido criado um núcleo específico da LBL em Maceió, sabe-se que ao menos cinco militantes se articularam com a Liga nos anos 2000, a partir do relato de uma das entrevistadas. Nota-se que ações coletivas realizadas em articulação nacional fortalecem o movimento como um todo, pois enquanto os grupos lésbicos da cidade estavam em constante diálogo com a LBL, participando de atividades de cunho nacional como jornadas pelo Brasil, organizados pelo Fórum de Mulheres - ligado a Articulação de Mulheres Brasileiras - junto com a Liga e ABGLT e construindo, inclusive, a Semana da Visibilidade Lésbica com este apoio que aconteceu nos anos de 2004, 2005, 2006 e 2008 -, eles se mantinham mais ativos e mobilizados, além de discutir questões, para além da lesbianidade em si, como o machismo e o patriarcalismo.

Como citada por uma entrevistada, temos como uma conquista a construção do primeiro plano de políticas e direitos para este público em Maceió, o Plano Municipal de Políticas para o Público LGBT, através da parceria entre o movimento e a Secretaria Municipal de Assistência Social de Maceió.

[...] o Estado poderia ter avançado muito mais se o Estado tivesse conseguido, por exemplo, implementar o SPE, que é proposta de todas as conferências, que é Saúde e Prevenção nas Escolas, que trabalha os eixos fundamentais, de saúde sexual reprodutiva, violência de gênero, enfrentamento ao racismo, enfrentamento a homofobia, lesbofobia e transfobia e prevenção às drogas. O SPE desde que foi lançado no governo Lula, ele foi implementado em $100 \%$ das escolas em Porto Alegre e Porto Alegre conseguiu reduzir os índices de violência homofóbica, lesbofóbica. No Estado de Alagoas a gente tem menos de $5 \%$ implementado nas escolas. E também tem outros programas... Também tem uma diferença muito grande se a gente compara a década de hoje com a década passada. A primeira vez que nós tivemos escrito num material oficial do governo a palavra políticas públicas para população LGBT foi no segundo governo do Fernando Henrique Cardoso. No primeiro governo Lula, a gente conseguiu lançar o primeiro Plano Nacional Brasil sem Homofobia e depois nós conseguimos lançar dois Planos Nacionais de Direitos Humanos que nos dois últimos governo de Lula e no governo de Dilma conseguiu, mesma ela tendo vetado o kit Brasil sem Homofobia, mas não podemos negar que houveram grandes avanços nesse aspecto para essa população. Óbvio que nada se dá de graça e existe conquistas graças ao movimento LGBT que vai lá, levantam suas bandeiras, bota a cara (E1). 
Outro ponto destacado pela militante relaciona-se à $1^{\text {a }}$ Conferência Nacional GLBT, em 2008, e a alteração do termo GLBT em favor de LGBT, uma conquista para as mulheres lésbicas após anos invisibilizadas dentro do próprio movimento, também preso a práticas machistas e individualizantes. A ex-militante entrevistada da LBL coloca:

[...] por causa dessa inversão da letra era uma guerra contínua entre os gays porque eles disseram "não, isso é ilógico, porque o movimento gay quem organizou fomos nós”, pois é, mas nós entendemos que o movimento foi organizado coletivamente, mas a história do machismo muito arraigado em todos os espaços e os gays eles se sentiam incomodados, né? E esse incômodo era em torno de um micropoder e nós continuamos discutindo ou trazendo nos nossos documentos o termo lésbica na frente. Aí começou essa história até que aconteceu a $1^{a}$ Conferência Nacional quando o presidente Lula foi fazer a abertura da Conferência e falou o termo LGBT e aí a gente começou a gritar que o nome do movimento seria LGBT, ou seja, passamos uma manhã inteira até umas $14 \mathrm{~h}$ da tarde discutindo só a inversão do $\mathrm{L}$ e do $\mathrm{G}$ dentro da Conferência para você ter uma ideia de como era polêmica essa questão, né? Porque pra muita gente pode não ter nenhum significado, mas pra gente tinha um significado simbólico, mas principalmente um significado político, que era a visibilidade das mulheres nos espaços políticos (E1).

Marcelino (2016) corrobora a fala acima sobre a importância política de uma mudança de sigla quando afirma que quebrar o silêncio no universo das mulheres é um exercício político, uma vez que o gênero, a cor, a classe e a orientação sexual implicam em estigmas e preconceitos. Estes são desafios diários de todas nós mulheres constituintes deste mosaico de diversidade e complexidade. No cotidiano de uma sociedade que é marcada pela forte presença das múltiplas identidades, aquelas que se desviam da lógica socialmente construída tendem a compor o quadro estatístico da violência.

Outra conquista levantada por uma das militantes adentra no campo jurídico. Em 2011, foi reconhecida a união estável entre pessoas do mesmo sexo pelo Supremo Tribunal Federal (STF), que consequentemente veio a possibilitar a adoção de crianças por casais homoafetivos ao abranger a compreensão do conceito de família.

\section{Articulações e divergências com outros grupos LGBTs}

Os grupos de lésbicas sempre mantiveram diálogo com outros grupos do movimento LGBT apesar de suas divergências. Os pontos de interlocução existem, segundo as participantes da pesquisa, quando se pensa na perspectiva da construção 
de políticas públicas, como por exemplo, em uma educação sem homofobia, que não seja baseada na divisão social do sexo, na discussão, no contexto da saúde e um atendimento efetivo e humanizado à população LGBT, além da questão da violação dos direitos humanos e o enfrentamento ao preconceito. Ainda acrescentam a própria Parada da Diversidade e a realização de seminários.

Olhe, os pontos de encontro é que existem as comissões de muitos setores daqui de Alagoas, por exemplo, Secretaria Estadual de Saúde, Secretaria municipal de Saúde, na educação estadual e municipal, ministério público, nesses setores de secretaria assim. Aí se faziam muitas reuniões, que eu participei, para que se formassem comissões e a gente soubesse dos trâmites direcionados ao LGBT. O que podia, o que não podia, o que eles achavam que não podia e a gente dizia que podia (E3).

No entanto, a problemática gira em torno do método político e das parcerias financeiras. O próprio conceito de liderança diverge entre o movimento de lésbicas e o movimento LGBT como um todo.

Para nós mulheres, para nós, lésbicas, a liderança tinha que estar nas bases, tinha que ir às bases. Algo que não estava impregnado no discurso, mas estava impregnado nas práticas dos homens, era que a liderança é aquele que chega mais alto. Então, para muitos, o método político não era discutido como a gente discutia. A gente vai até aqui, por exemplo. Muitas vezes a gente discutia, até que ponto vale a pena você receber recursos para uma determinada ação e você não conseguir problematizar politicamente determinadas questões politicamente de forma livre [...] Hoje, 10 anos, 7 anos depois, eu digo que a cada ano nós vivemos uma nova conjuntura, talvez nós pensássemos diferente. Talvez não. Mas naquele momento, para nós era extremamente importante essa liberdade, da gente discutir livremente, propor livremente, de ir para o enfrentamento com o estado, com o governo federal, porque nós sabemos que boa parte do movimento social termina vindo das bases dos movimentos, dos partidos mais de esquerda, mas acho que isso fez muita gente amadurecer (E1).

Conforme Silva (2006), no processo de construção da Parada, se fazem presentes elementos individuais, coletivos e as expectativas sociais dos/as participantes a respeito de si e dos/as outros/as. E são essas expectativas que podem, ao assumir um sentido quando se materializam em ação, mobilizar ou não a participação das pessoas que se reconhecem nesse universo.

A Parada da Diversidade tornou-se um dos principais instrumentos para o movimento homossexual (re)afirmar a sua existência enquanto movimento político, perante a sociedade e aos órgãos públicos. No entanto, a concepção de Parada e sua 
importância entre os grupos mostram-se discrepantes. A Parada é encarada pelas entrevistadas como um espaço político reivindicatório, porém elas enxergam sua configuração atual como evento festivo: "a gente ia pra parada, tentou levar a nossa representatividade. Não lembro a Parada, acho que foi em 2007, a gente construiu a Parada junto. Só que aqui, não só aqui como em todo lugar, a Parada é mais visada pra festa, não tem debate político" (E5).

Assim como discute Silva (2006), nesse processo, muitas vezes os interesses eleitos como prioritários não são acordados por todos/as os/as participantes e são estes interesses divergentes que marcam os processos de produção coletiva da Parada e da consciência daqueles que se envolvem nela, mesmo que o engajamento signifique discordância e desentendimento com a linha que dá o tom geral da ação. Os movimentos aparentam seguir a lógica hierárquica baseada no gênero, mantendo uma estrutura vertical das relações sociais. A fala a seguir exemplifica o posicionamento do autor:

A gente é muito parceiro do GGAL, do Pró-vida, entendeu? Só que a gente é parceiro, mas entendeu uma coisa: gay é gay, lésbica é lésbica. Quando vem projetos 'vamos sentar!' Não vai dividir pra lésbica, entendeu? Lésbica só fica como se fosse... 'ah, ajuda ali na mesa' A gente sabe que cada um tem que seguir seu objetivo, mas quando se conta dinheiro, parcerias financeiras, lésbicas não tem vez $\left(E_{4}\right)$.

Concordando com Silva (2006), percebemos a impossibilidade da existência de um movimento LGBT unitário e por isso ele utiliza o termo movimentos, enaltecendo a sua pluralidade, e o fato de que as pautas reivindicatórias nem sempre são convergentes e podem, inclusive, competir entre si. Isso se torna ainda mais claro quando se percebe que é urgente e lento o processo de desconstrução de práticas machistas e androcêntricas, mesmo em movimentos voltados a segmentos da sociedade que são alvos de estigmas e preconceitos.

Para Machado (2007), para que esses movimentos sociais consigam argumentar com o Estado e com a sociedade em geral, novas formas de articulação com estes atores e maior conhecimento acerca das dinâmicas políticas contemporâneas devem ser efetivadas, desenvolvendo formas criativas de enfrentamento. Além disto, o autor aponta que é necessária uma horizontalidade no interior dos grupos, para que os integrantes possam atuar de forma mais democrática nas decisões coletivas.

\section{Considerações finais}

A história de construção e fortalecimento do movimento lésbico parece repetir-se nas regiões do país, mesmo ocorrendo em épocas distintas. Conforme Lessa (2007), as migrações de ativistas de um grupo para outro, divergências entre 
grupos e a ascensão de um grupo sobre os outros, são algumas características que se percebem no decorrer da análise dos movimentos de lésbicas.

Ao reconstruir esta história, deparamo-nos com práticas machistas e patriarcais dentro do próprio movimento LGBT. As mulheres, em especial as lésbicas, ainda são colocadas em um patamar inferior e frágil, e, ao introjetarem tais características, muitas delas se protegem na invisibilidade. Devido a isso, o reconhecimento e visibilidade deste sujeito político ainda é a principal bandeira de luta do movimento das mulheres lésbicas e uma das maiores dificuldades para o seu fortalecimento.

Em Maceió, observou-se, através das vivências relatadas, a existência efêmera dos grupos e a quantidade insuficiente de militantes. Dos quatro grupos que tentaram avançar no que tange o reconhecimento político, apenas um considerase atuante atualmente, embora as militantes se sintam um pouco desmobilizadas. Isso se dá pela desarticulação com outros grupos LGBTs que ainda não conseguem atuar, muitas vezes, de maneira horizontal. pela falta de recursos financeiros e de infraestruturas para a realização de reuniões e planejamento de ações. Além disso, percebe-se a necessidade de articulação com o movimento nacional de lésbicas para o fortalecimento de suas pautas. Pode-se concluir também que o medo da exposição das mulheres em serem reconhecidas enquanto ativistas lésbicas sobrecarrega aquelas que lutam, as quais ficam divididas entre a militância e a sua própria sobrevivência.

A Parada da Diversidade, enquanto símbolo reivindicatório da luta LGBT, atua politicamente no sentido de tentar descontruir padrões hegemônicos, porém, na visão das entrevistadas, não parece ser tão eficaz devido ao seu caráter festivo. Silva (2006) aponta que a Parada vem a ser um importante veículo de politização e formação de consciências mais afeitas ao coletivo, mesmo sendo rodeada por interesses de mercado que nem sempre se revertem em benefícios para o grupo organizador. Porém, os discursos das participantes desta pesquisa denotam insatisfação quanto à postura política e aos interesses econômicos dominados pelo grupo majoritário em Maceió.

A cidade, considerada retrógrada em alguns aspectos devido a sua herança coronelista, conseguiu ter alguns direitos conquistados pelo público LGBT. Porém, o segmento lésbico, em específico, ainda precisa avançar no quesito de reconhecimento de suas especificidades, como por exemplo, na área da saúde, pois apesar da existência de uma Política Nacional de Saúde Integral LGBT, além de cartilhas de saúde para mulheres lésbicas e bissexuais, as posturas tomadas por profissionais não são coerentes com as proposições da política.

Pensar e falar sobre lesbianidade requer falar sobre patriarcado, machismo e lesbofobia, sobre categorias cristalizadas em posições dicotômicas: homem/mulher, heterossexual/homossexual, preto/branco. Portanto, não é um movimento para mulheres e sim para toda a sociedade. Os discursos presentes no trabalho são recortes de histórias de luta de mulheres que, apesar de tantos processos deslegitimadores da lesbianidade, buscam ser protagonistas de suas próprias vidas. 


\section{Referências}

FACCHINI, Regina. (2005). Sopa de Letrinhas? Movimento homossexual e produção de identidades coletivas nos anos 9o. 1 ed. Rio de Janeiro: Garamond.

LESSA, Patrícia. (2007). Lesbianas em movimento: a criação de subjetividades (Brasil, 1979-2006). Tese (Doutorado em História) - Programa de Pós-graduação em História, Universidade Federal de Brasília, Brasília, mimeo.

MACHADO, Frederico Viana. (2007). Muito além do arco-íris: A constituição de identidades coletivas entre a sociedade civil e o Estado. Dissertação (Mestrado em Psicologia Social) - Programa de Pós-graduação em Psicologia, Universidade Federal de Minas Gerais, Belo Horizonte, mimeo.

MARCELINO, Sandra Regina de Souza. (2016). "Entre o racismo e a lesbofobia: relatos de ativistas negras lésbicas do Rio de Janeiro". Gênero, n. 2, 16: p. 111-129, jan-abr.

MARTINHO, Míriam. (2006). Dia da visibilidade lésbica: 10 anos de uma história mal contada. Boletim Um Outro Olhar, número o9. Disponível em http://www. umoutroolhar.com.br/2017/o8/dia-da-visibilidade-lesbica-21-anos-de.html Acesso em 25 de outubro de 2017 .

OLIVEIRA, Vanilda Maria de. (2007). "Identidades interseccionais e militâncias políticas”. In: GROSSI, Miriam Pillar (org.). Conjugalidades, parentalidades e identidades lésbicas, gays e travestis. 1 ed. Rio de Janeiro: Garamond. p. 385-401.

PINAFI, Tânia; PERES, Wiliam Siqueira. (2010). "Cartografias das produções discursivas nos Movimentos de Gays e Lésbicas: (Im)possibilidades dentro do sistema andro-heterocêntrico". In: SEMINÁRIO INTERNACIONAL FAZENDO GÊNERO DIÁSPORAS, DIVERSIDADES, DESLOCAMENTOS, 9, Florianópolis. Anais eletrônicos do Seminário Internacional Fazendo Gênero: Diásporas, Diversidades e Deslocamentos. Florianópolis: Universidade Federal de Santa Catarina. p. 1-7. Disponível em: <http:// www.fazendogenero.ufsc.br/9/site/anaiscomplementares\#php2go_top> Acesso em 26 de out. 2017 .

SELEM, Maria Célia Orlato. (2007). A Liga Brasileira de Lésbicas: produção de sentidos na construção do sujeito político lésbicas. Dissertação (Mestrado em História) Programa de Pós-graduação em História, Universidade de Brasília, Brasília, mimeo. 
SILVA, Alessandro Soares da. (2006). Marchando pelo Arco-Íris da Política: A Parada do Orgulho LGBT na Construção da Consciência Coletiva dos Movimentos LGBT no Brasil, Espanha e Portugal. Tese (Doutorado em Psicologia Social) - Programa de PósGraduação em Psicologia Social. Pontifícia Universidade Católica de São Paulo, São Paulo, mimeo.

SOARES, Gilberta Santos; COSTA, Jussara Carneiro. (2012). "Movimento lésbico e Movimento feminista no Brasil: recuperando encontros e desencontros". Labrys, études féministes/estudos feministas, v. 2, p. 1-64, jan-jun.

SOARES, Gilberta Santos; SARDENBERG, Cecília Maria Bacellar. (2011). "Assumindo a lesbianidade no campo teórico feminista". In: CONGRESSO BRASILEIRO DE SOCIOlOGIA, 15, Curitiba. Anais do XV Congresso Brasileiro de Sociologia Mudanças, Permanências e Desafios Sociológicos. Curitiba: Sociedade Brasileira de Sociologia. p. 1-17. Disponível em: <http://www.sbsociologia.com.br/portal/index. php?option=com_docman\&task=search_result\&Itemid=171>. Acessado em 26 de outubro de 2017.

WITTIG, Monique. (2006). El pensamiento heterosexual y otros ensayos. $1^{\mathrm{a}}$ edição. Madri: Egales.

Recebido: 01.11.2017

Aceito: 30.09.2018 